\title{
La ciudad y el ciudadano en Egipto
}

\author{
Félix Alonso y Royano*
}

\begin{abstract}
RESUMEN
ABSTRACT

El autor, sobradamente conocido entre nosotros por sus colaboraciones sobre su especialidad en el Derecho de la Antigüedad en el Próximo Oriente, fundamentalmente en el derecho de familia, hace en este trabajo un bosquejo sobre la ciudad y el ciudadano en el Egipto faraónico, materia muy querida para él, sobre un mundo que tan bien conoce, distinguiendo y sistematizando 3 modelos de ciudad: Las ciudades templo, las ciudades-fortaleza y las ciudades artesanos, dando asi un panorama completo, junto a la existencia de aldeas y caserías diseminadas, los lugares fundamentales de poblamiento $y$ núcleos de población que por sus características arquitectónicas, religiosas, administrativas y militares, conformaron la sociedasd egipcia,

The author, known between us extremely well due to his collaborations on his speciality about the Right of Antiquity in the Middle East, fundamentally in the family rights, carries out in this work a study about the city and the citizens in the pharaonic Egipt, which is a much beloved matter for him, about a world he knows so well, distinguishing and systematizing three typess of city: the temple cities, the fortress cities and the artisan cities, giving that way a complete panorama, together with the existence of villages and disseminated country houses, the inhabitated fundamental places and centres of population that because of their architectural, religious and military characteristics conformed the egyptian society, especially in the Middle and New Empires.
\end{abstract}

* Doctor en Derecho. Miembro de la Fondation Egyptologique Reine Elisabeth Bruxelles. Profesor-Tutor de Historia del Derecho y las Instituciones en el C.A. "Bizkaia" de la UNED. 
sobre todo en los Imperios Medio y

Nuevo.

Describe después al ciudadano como

habitante de esas ciudades y sus costumbres alimenticias, de vestido $y$, en una palabra, el "estatus" social y la protección del derecho, dando una visión general -como no podía ser menos-dadas las dificultades de concretización en un imperio que duró

3.000 años a.C.J. Habitante de un mundo que, por otro lado, y a pesar del tiempo transcurrido, se nos hace cercano a nosotros.
After he describes the citizen as an inhabitant of those cities and their food, costume customs, in one word the social "status" and the protection of the law, offering a general vision as could not be less- because of the specification difficulties in an Empire that lasted 3.000 years B.C. Inhabitant of a world that, although the course of time remains close to us.

Este trabajo está dedicado a mi querido amigo Juan Santos Yangüas,

Catedrático de Historia Antigua de la UPV.

Como ya explicitamos en «Instituciones familiares en el Egipto faraónico» 1, primero y después en nuestro libro «El derecho de familia en el Egipto faraónico" ${ }^{2}$, cuya edición notablemente ampliada se prepara en estos momentos; y de acuerdo con Martín Bernal 3; y con mi querido amigo Ferrán Iniesta ${ }^{4}$, ya desde el Coloquio de la UNESCO de 1974, siguiendo a Diop ${ }^{5}$ y a Obenga ${ }^{6}$ fundamentalmente, y después a Vercoutter, Blanc y Leclant ${ }^{7}$, así como también a Avdiev ${ }^{8}$, hoy día está clarificado que el antiguo pueblo egipcio fue camita, y su parentesco, tanto lingüístico (gallo, somalí, wolof, swahili «bantú», etc.) como antropológico (medición craneal en sepulturas arcaicas de Nagada), no deja lugar a dudas. De tal suerte que los intentos por parte de algunos histo-

\footnotetext{
1 Tesis doctoral, leida el 21 de enero de 1994 en la Facultad de Derecho (Dpto. de Historia del Derecho y las Instituciones) de la UNED.

2 Edit. Lepsius, s. I. Valencia, 1995 y EUE, Bilbao, 1996

3 “Atenea negra». Edit. Crítica. Barcelona, 1993.

4 "Antiguo Egipto. La nación negra". Edit. Sendai. Barcelona, 1989.

5 Diop, Cheikh Anta. Nations négres et culture; de l'Antiquitè négro-égyptienne aux problémes culturels de l'Afrique noire d'aujourd'hui. París. Présence Africaine, 1955.

- Obenga, T.: L'Afrique dans l'Antiquité: Ėgypte pharaonique, Afrique noire. Paris. Présence Africaine, 1973.

7 VERCOUTTER, J.; BLANC, N.; LECLANT, J. et alii: «Poblamiento del antiguo Egipto y desciframiento de la escritura meroítica». Serbal/UNESCO. París, 1983.

8 AvDIEV, V. I.: «Historia económica y social dcl Antiguo Oriente». Akal. Madrid, 1986.
} 
riadores que aún pretenden demostrar su origen lingüístico y cultural asiático-semita son absolutamente erróneos. Sin que esto quiera decir que, en oleadas de invasiones pacíficas a lo largo de su historia antigua (incluidos los hicsos), no fuesen mezclándose diferentes razas, lenguas y culturas periféricas.

La pretensión de este trabajo, dado que los límites establecidos impiden otro tipo de tratamiento, profundo y exhaustivo, será la de hacer un bosquejo superficial sobre la ciudad y el ciudadano (con todas las connotaciones que pueden hacerse a estas expresiones), para lo cual distinguiremos, respecto a la ciudad ${ }^{9}$, algunos modelos como las ciudades-templo (Karnak/Tebas/Akhetatón), las ciudades-fortaleza (Elefantina y Buhen) y las ciudades-artesanos (Deir-el Medina y Kahun); y respecto al ciudadano/habitante, su papel como súbdito y como administrado. Todo ello nos lleva a contemplar la organización social; es decir la agricultura y la ganadería, el comercio y la administración de justicia; y la administración pública desde la óptica estatal y desde la religiosa.

Se ha dicho, hace pocas décadas, que la cultura egipcia era una civilización carente de ciudades como centros culturales. Y si bien esta afirmación (un tanto gratuita) puede permitirse para el Imperio Antiguo, o "cultura de las pirámides", no podemos estar acordes con la inexistencia de ciudades egipcias como estructuras edificadas, o construcciones, con una administración, palacios, templos, villas, viviendas de diferentes categorías sociales, calles de tránsito peatonal y rodado, que acreditan un asentamiento permanente, expansivo y, además, evolutivo. Bien es cierto, y esto acredita lo que acabamos de decir, que se ha demostrado arqueológicamente que los edificios nuevos solían asentarse sobre construcciones venidas abajo en períodos cortos (30/40 años) y cuyos ladrillos de adobe significaban los cimientos de las nuevas construcciones. De modo que ese «modus operandi» ha dificultado un estudio arqueológico definitivo al desaparecer los depósitos de escombros urbanos con su utilización como nuevos cimientos o incluso, como "sejab" o abono por los "fellah" egipcios.

Egipto, como no podía ser menos por su ubicación temporal en la historia, es un Estado fundamentalmente agrícola, necesariamente artesanal,

9 No entraremos en descripciones de las distintas capitales que tuvo Egipto, comenzando por Ineb Heg (Muro Blanco), esto es Mentis capital del Imperio Antiguo, fundada por Aha («Alcón combatiente") fue en principio una ciudad fortaleza, rodeada de murallas y situada en un lugar estratégico, que a partir de Zoser se convierte en residencia real y sede de la administración central. 
suficientemente comercial y tangencialmente (en gran medida como lastre religioso), interesantísimamente técnico, como lo acredita la metalurgia del bronce, para no citar sus ciclópeas construcciones del Imperio Antiguo y de conocimiento universal. Los monumentos pétreos y las ideas irrigatorias a través de construcciones hidrotécnicas dan fe de lo que antecede. $Y$ buena prueba de ello es la construcción de esclusas y diques que vertían el agua sobrante del Nilo en el embalse de El Fayum, para volver nuevamente al río, dando nacimiento a la ciudad de Kahun, por ejemplo.

Ya Petrie ${ }^{10}$ primero, y Ricke ${ }^{11}$ después, trabajaron en excavaciones ciudadanas, y aquél en la de esta ciudad artificial destinada a los obreros de la pirámide de Sesostris II. En la figura 1 se puede observar el plano horizontal de una amplia casa de un alto funcionario situada en el norte de la ciudad. La superficie de las viviendas oscilaba entre los $100 \mathrm{~m}^{2}$ y los $2.400 \mathrm{~m}^{2}$.

De modo que la agricultura conlleva el desarrollo de la producción artesana incrementada por la herramienta broncínea y la producción textil del lino como materia prima, hasta la construcción, primero, de barcos fluviales con madera de cedro libanés y pino de Cilicia, al objeto de ejercitar el transporte tanto de elementos pétreos para las grandes construcciones de templos y otros monumentos, hasta el ejercicio, después, del comercio interior y exterior, primordialmente este último con Palestina y Siria. Ahí están las expediciones comerciales al País de Punt o a los oasis occidentales, todo lo cual da como consecuencia la explotación minera de cobre en el Sinaí, o de oro en el "despreciable País de Kush» (Nubia), y consecuentemente la colonización de regiones limítrofes y la construcción y fortificación de vías de comunicación, como la tan conocida de UadiHammamat uniendo el Valle nilótico con el litoral del mar Rojo, o la de Elefantina,capital del primer nomo del Alto Egipto, con las tierras del sur.

Según Avdiev uel desarrollo de los oficios y del comercio contribuyó a la aparición y crecimiento de las ciudades». Sin embargo en Egipto es difícil dar una explicación científica de la ciudad. Soulié ${ }^{12}$ expresa que "La única capital excavada de manera científica es Tell el-Amarna: Pero ¿cómo comparar una ciudad nueva, cuya ocupación sólo se ha producido durante una corta duración, con una capital (Tebas) que tardó varios siglos en formarse? Menfis es mal conocida, y los demás emplazamientos urba-

PetRie, W.M.F.: llahum, Kahum and Gurub. Londres, 1891.

RICKE: Der Grunddriss des Amarnawohnhauses. Leipzig, 1931.

12 SOULIE, D.: "La ciudad y su población bajo los Ramsés" (Tebas). Alianza Editorial. Madrid, 1992. 


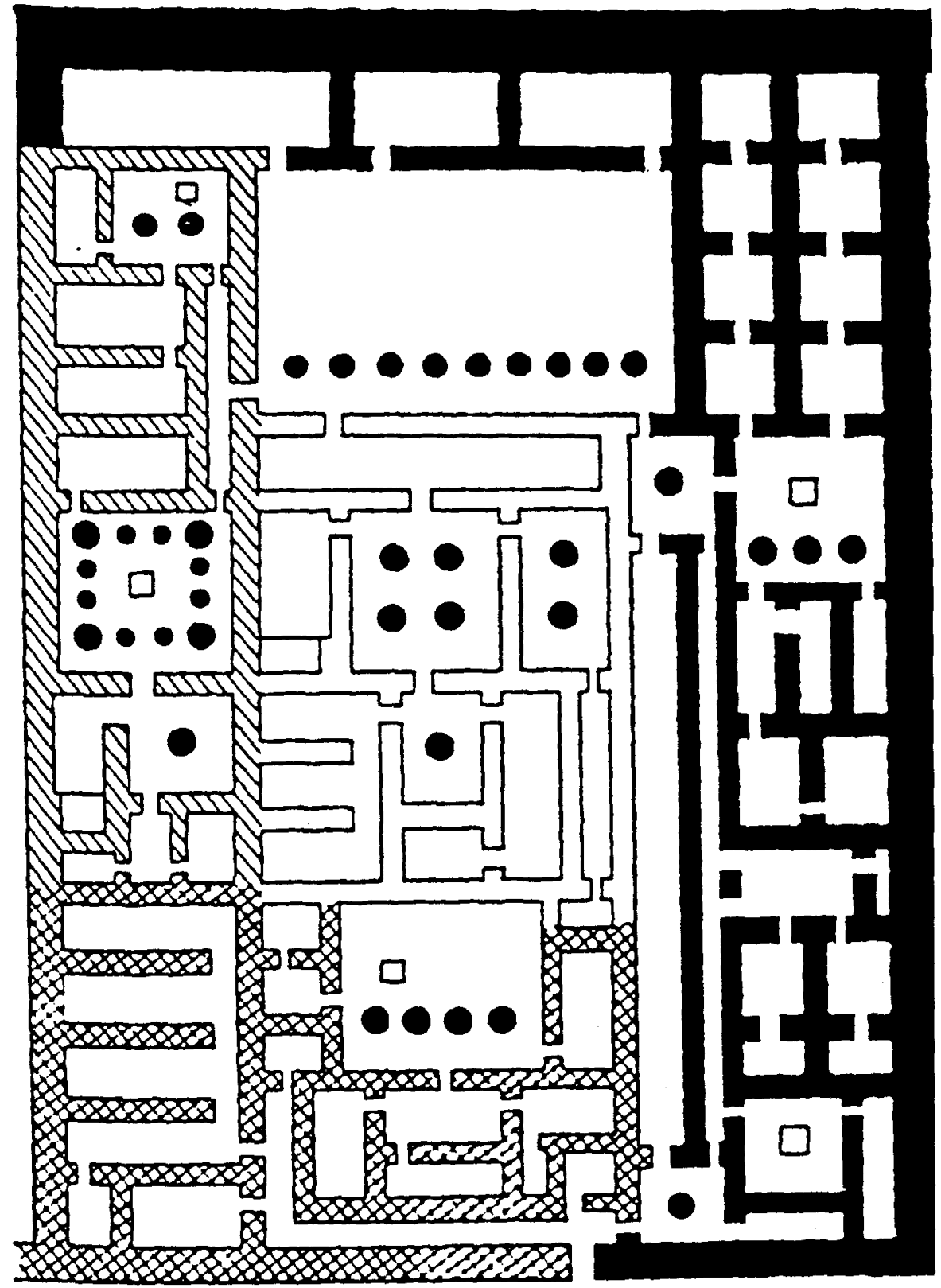

Figura 1. 
nos estudiados son de pequeño tamaño. Nuestro conocimiento de la ciudad sigue siendo pues muy hipotético". De modo que conocemos mejor al ciudadano que a la ciudad. $Y$ con ese, al parecer, principio, trataremos de explicar mejor la organización social y la administración pública, que el «habitat in situ» arqueológico y arquitectónico.

En la figura 2 se describe el plano horizontal de una vivienda de $500 \mathrm{~m}^{2}$ situada en la ciudad de Akhetatón (finales de la XVIII dinastía) que acredita a su propietario como un funcionario de relativa categoría.

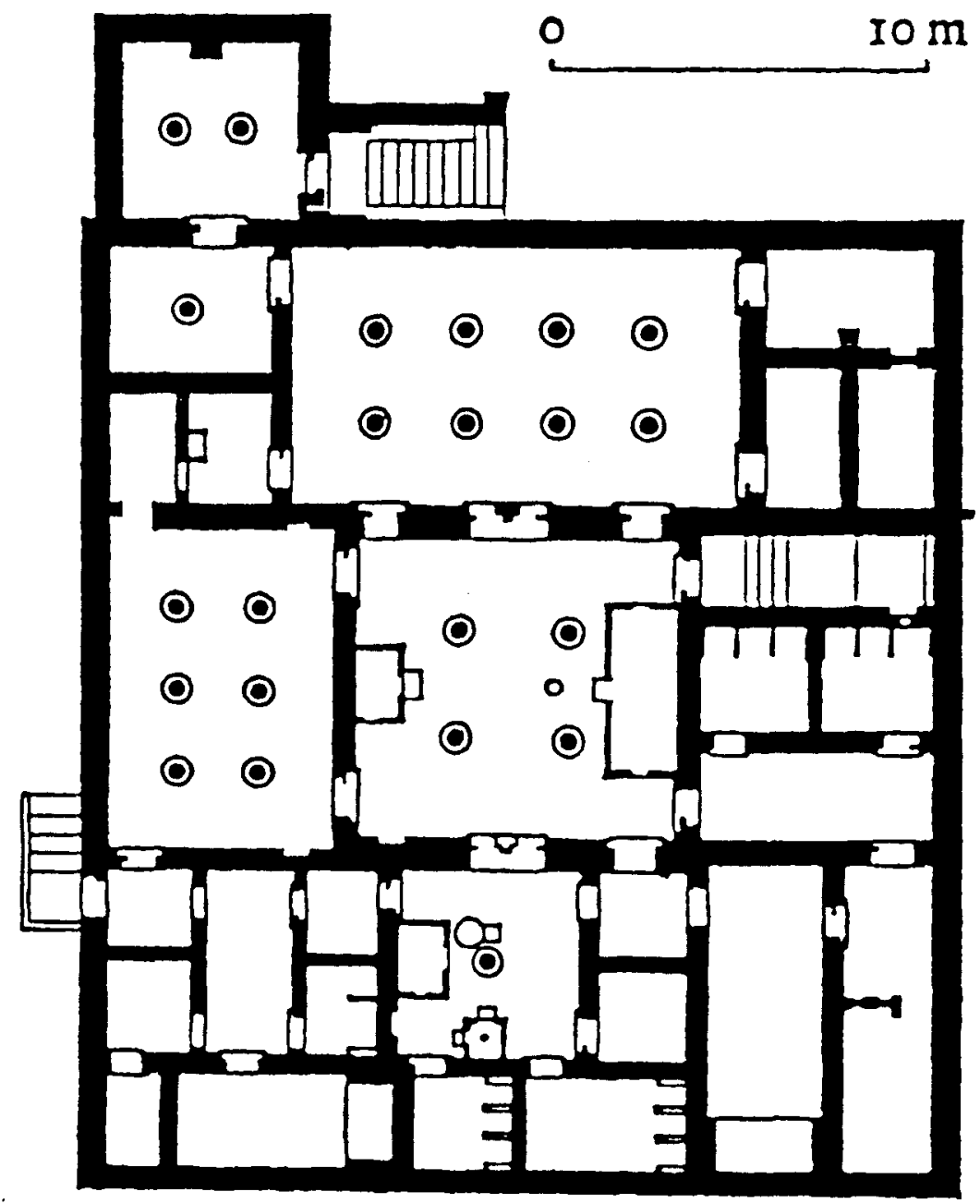

Figura 2. 


\section{LAS CIUDADES-TEMPLO}

Karnak/Weset (Tebai, para los griegos).Tebas: Karnak, como nombre árabe actual, es la «ciudad templo de Amón»; Weset la ciudad administrativa. En el Imperio Medio (2060/1785), y en la XII dinastía, el Horus Kheperkare' (Sesostris I. 1962/1926 a.C.) erige una capilla en Karnak, y en el Segundo período intermedio los últimos soberanos de la Dinastía XVII reinan ya en Tebas. La ciudad-templo se mantiene a través del tiempo gracias a su pétrea construcción, pero no así la ciudad-administrativa, construida con ladrillo crudo que acabó convirtiéndose en limo. No podemos olvidar que la moderna Luxor se asienta sobre la antigua Tebas. De modo que siendo imposible una excavación científica, nuestro conocimiento sobre Tebas es altamente hipotético. No digamos nada respecto a su población. Es imposible sospechar siquiera la concentración urbana de la ciudad. Parece probable que el eje longitudinal fue la avenida de las esfinges habidas entre el templo de Karnak y el de Luxor, y a su derredor podrían haber estado situadas casas, almacenes y edificios naturalmente las de altos administrativos, funcionarios y militares. Mayor duda nos asalta respecto a la ubicación del palacio real. Es probable que concretamente, ya en la XVIII dinastía, Amenofis III tuvo el palacio de Malqatta en la orilla izquierda, naturalmente fuera del límite de inundación del Nilo; es decir, frente a la ciudad-templo y a la ciudadad-ministrativa, a modo de retiro alejado del bullicio de la populosa Weset.

La descripción de una villa de un alto funcionario, si tomamos como ejemplo tanto las decoraciones que adornan las tumbas de las necrópolis, como los modelos de barro que han llegado hasta nosotros, podría ser: Un recinto protector cuadrangular dentro del cual se encontraba un jardín arbolado, entre lo que cabe destacar, junto a las palmeras datileras comunes, y las llamadas de castaños de indias, las palmeras "dwm" ${ }^{13}$ y los sicomoros, con un estanque en el que sobrenadan grandes manojos de lotos y entre los que nadan patos y ánades, así como una amplia casa, cuyo umbral suele estar emparrado de cepas que luego darán un vino malvasía para utilizar en la vivienda, y junto a ella un anexo compuesto por un granero, un almacén y la cocina. Además, las casas más pudientes disponen de un terreno hortícola de regadío a través de canales que provienen directamente de la orilla nilótica. Hasta tal punto que en muchas de

13 Especie de palmera cuyo tronco se divide en dos ramas que, a su vez, se divide en otras dos. Sus gruesos frutos eran muy estimados por los egipcios. Este tipo es más frecuente hallarlo remontando el Nilo en dirección a Siut, y cada vez es más raro verlo. 
esas casas existe un "sh3dwf" ${ }^{14}$. La fachada de la casa, construida con ladrillo crudo recubierto, a veces, de una capa blanca de estuco, normalmente carecía de ventanas exteriores, con la única abertura de la entrada en zig-zag que no permite ver el interior. Algunas casas probablemente eran de un nivel, otras de incluso dos o tres pisos. Tras la puerta de entrada a la vivienda se accedía a un amplio hall o vestíbulo, sostenido por 4 - 6 columnas de madera recubiertas con estuco y pintadas con motivos florales, y en cuyo centro incluso podría tener un pequeño estanque que daba frescor al ambiente, en un clima seco. Realmente era un patio interior al que daban las habitaciones privadas; esto es, dormitorios, comedor, salas de estar y servicios. Éstos eran simples retretes provistos de un asiento perforado y un recipiente con arena para recoger los detritus, pues para el baño corporal o de limpieza estaba el estanque exterior. Y para la «toillete» femenina ésta solía realizarse en el mismo patio central.

En las casas que disponían de varios niveles, se accedía a los pisos altos y azoteas a través de 2 tipos de escalera: La de escalones de fábrica, adosada a una de las paredes interiores, o la construida de travesaños de madera y que, generalmente, era móvil.

En los niveles superiores, los habitáculos disponian de pequeños lucernarios que dejando pasar la luz del sol, se protegían con esterillas vegetales (a veces, en las casas ricas, cortinillas de lino), para proteger del polvo desértico a los moradores.

Dentro de la casa vivía toda la familia, incluida la servidumbre, y a veces en recintos adosados, los animales domésticos. Siendo una sociedad patriarcal, el padre asumía el papel dirigente, y las esposas (entre los que podian permitirse el mantenimiento de más de una, ya que la ley no prohibía la poligamia ${ }^{15}$ ) la dirección de la casa y servicio.

La figura 3 nos describe la vista general de una vivienda excavada la pasada década situada en el sector occidental de Tebas, y probablemente perteneciente a un alto funcionario de los templos alli situados. El que

14 "Chaduf". Es decir un artilugio sobrepuesto entre dos vigas horizontales que, transversal y en uno de cuyos extremos hay un contrapeso, en el otro cuelga una tinaja de barro, o de cuero para sacar agua y, moviendo el palo horizontal, trasladarla al canal térreo que la verterá en el huerto. Ese tipo de regadío hortícola proporcionaba hortalizas para la manutención familiar y servil: cebollas, pepinos, guisantes y berenjenas, que entre otras, formaba el cotidiano alimento, junto a otros como la cerveza, la pesca, caza, etc., del pueblo egipcio. Pobres y ricos. Artilugio que el autor ha visto frecuentemente en el Egipto actual.

15 Vid. pág. 1 de este trabajo: Alonso y Royano, F.: Instituciones familiares en el Egipto faraónico (Tesis doctoral. UNED) y «El derecho de familia en el Egipto faraónico». Edit. Lepsius, Valencia y EUE, Bilbao. 
carezca de escalera de fábrica nos hace suponer que el edificio era de una sola planta. En la figura 4 se aprecia el detalle de su construcción con ladrillo de adobe, y al fondo, horno, cocina y almacén.

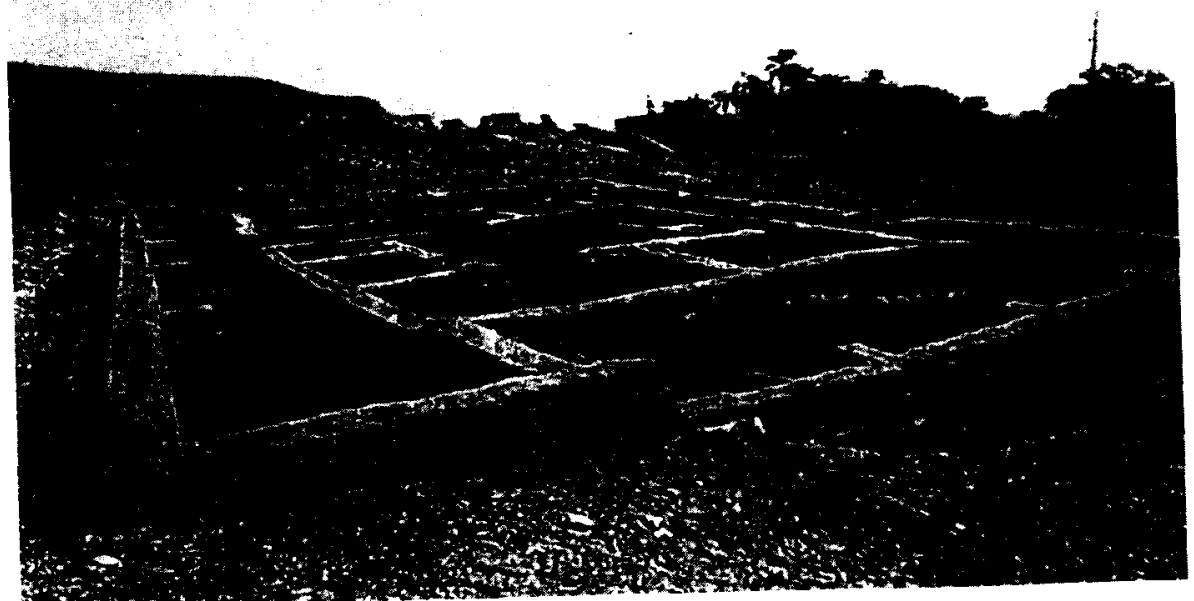

Figura 3.

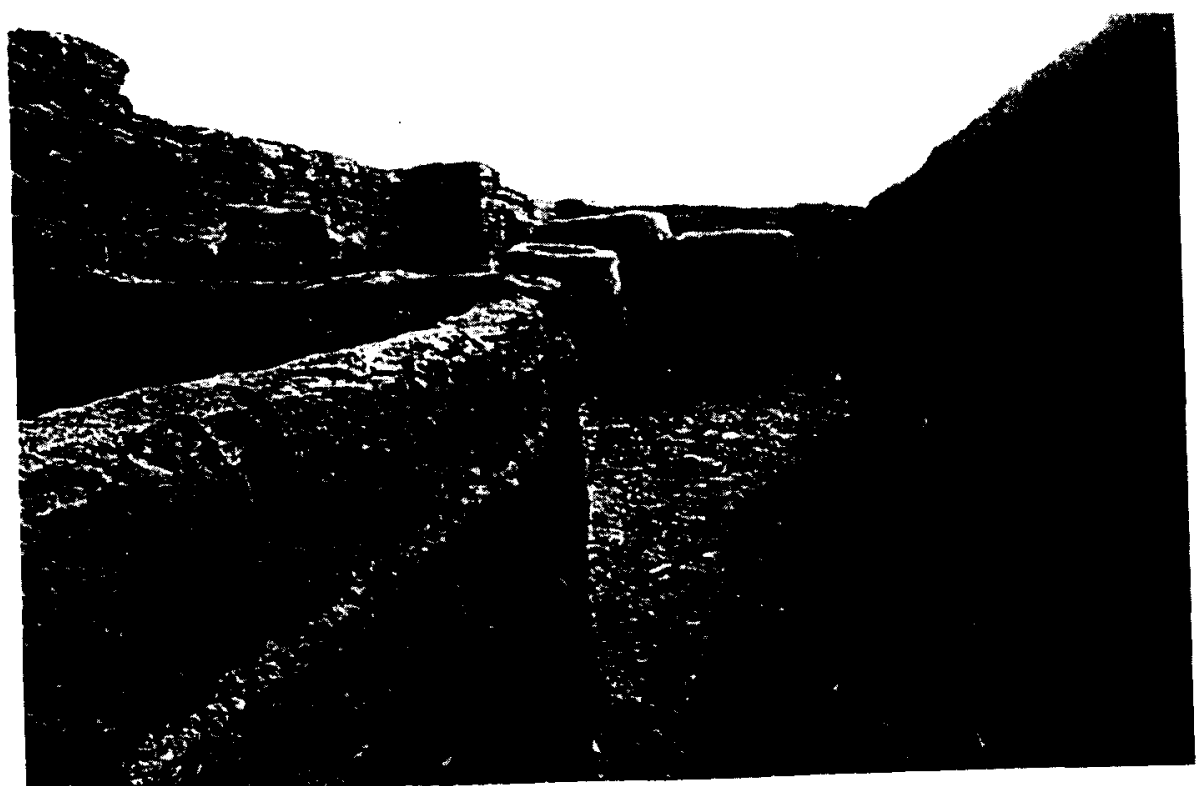

Figura 4. 


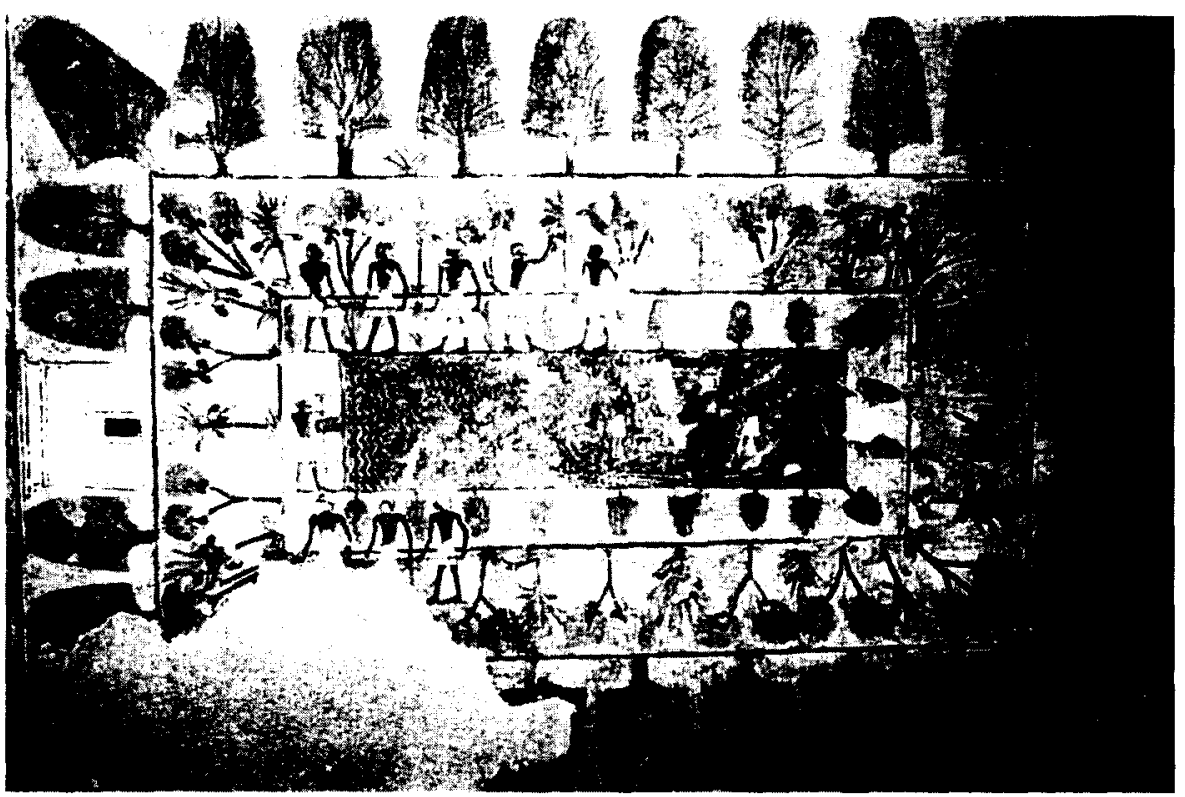

Figura 5.

El modelo de una villa tebana perteneciente a un alto funcionario nos lo puede dar la pintura mural del «H3ty» Rekhmire, exitente en la tumba $n^{\circ}$ 100 en Tebas (figura 5), donde los jardines, estanques, arbolado y huertos, nos llevan a imaginar la sensación de frescor, bienhestar y felicidad de aquellos privilegiados funcionarios en el caluroso clima egipcio, y ponerlo en contraposición a la maqueta de arcilla cruda del Primer período Intermedio (figura 6), o a la existente en el museo egipcio de Turín (Italia), de una humilde vivienda de adobe perteneciente al Imperio Medio (figura 7). Como se podrá apreciar, antes como ahora, la amplitud y comodidad de las viviendas dependía del «status» social y económico de sus propietarios. La comparación y cotejo entre las dos últimas y la descrita en la pintura mural en una tumba de la XII dinastía, en Illahum (figura 8), donde en su registro inferior se aprecia el detalle de las puertas enrejadas, con que se encontraban cerradas las habitaciones del piso inferior, no deja lugar a dudas.

Estos modelos pueden servirnos como ejemplo de conjunto de la ciudad en general. Las ciudades-templo no eran otra cosa que el conjunto de viviendas adosadas o cercana a los templos funerarios o religiosos, y sus habitantes los distintos tipos de sacerdotes-funcionarios, sacerdotes " $w 3 \mathrm{~b}$ " o sacerdotes al servicio de fundaciones funerarias erigidas en me- 


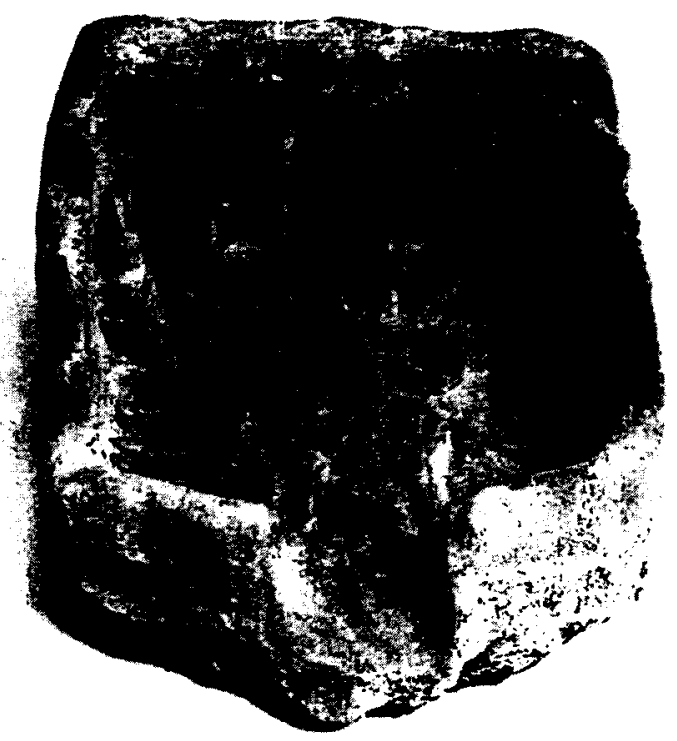

Figura 6.

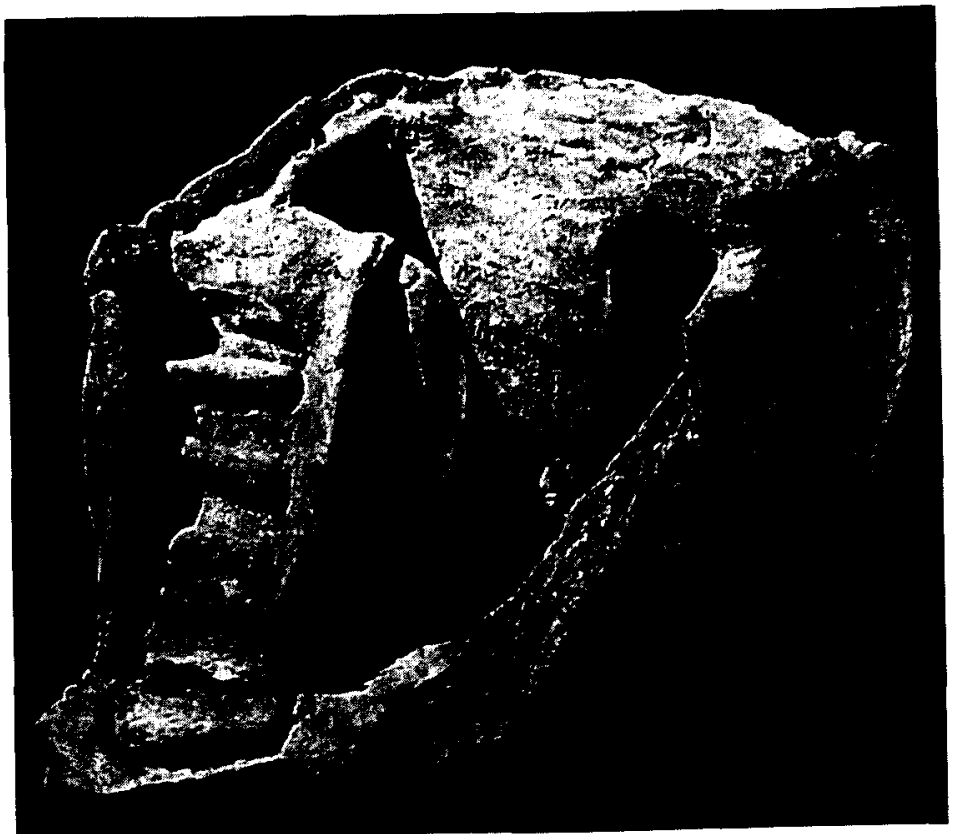

Figura 7. 


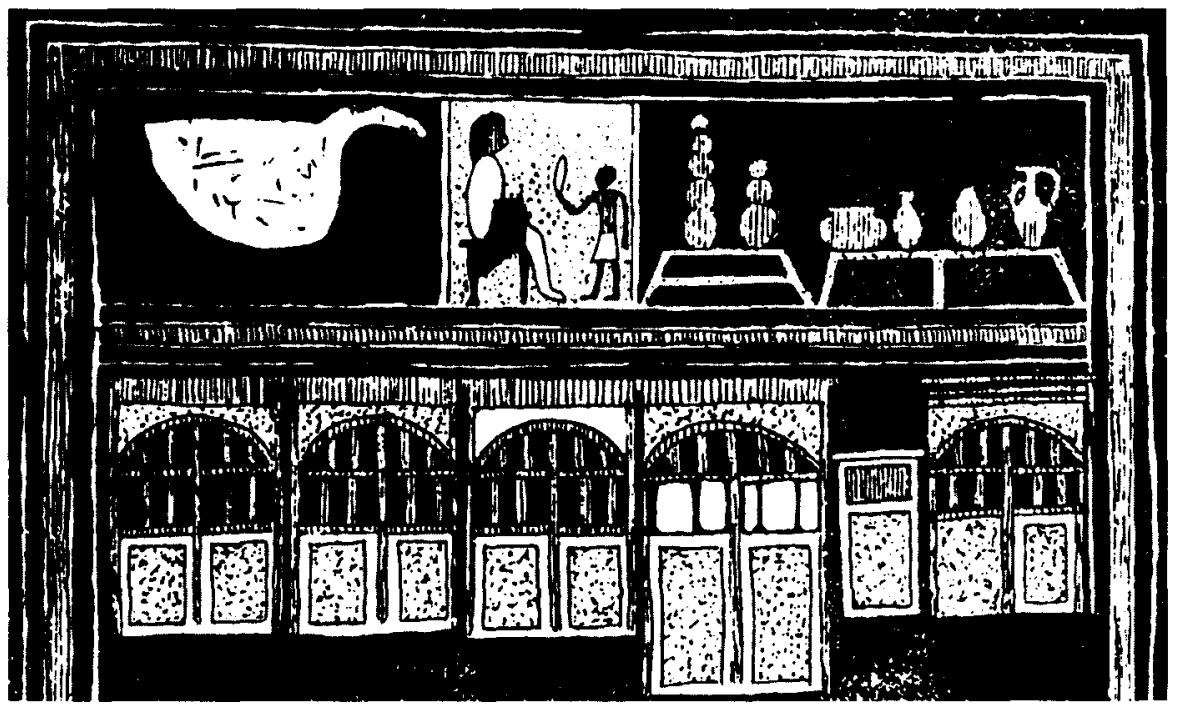

Figura 8.

moria de dioses, faraones o altos dignatarios, como ya han descrito suficientemente Revillout ${ }^{16}$, Pirenne ${ }^{17}$, Theodoridés ${ }^{18}$ y yo mismo.

De modo que la ciudad-templo, teniendo algunas particularidades respecto a la ciudad-administrativa, o ciudad-residencial, no tenían muchas diferencias estructurales 0 arquitectónicas respecto unas de otras. La diferencia estaba en la categoría de sus ocupantes; es decir de su "status" social y económico. $\mathrm{Y}$, como ahora, excepto las villas residenciales, retiradas 0 alejadas prudencialmente del conglomerado urbano, dispuestas en barrios se encontraban las casas de los pobres y de los pudientes.

Mención aparte hay que hacer al hablar de Akhetatón, por ser casi la única ciudad excavada científicamente y cuya descripción nos llevaría un grueso volumen. Se trata de una ciudad de nueva planta, de finales de la XVIII dinastía, erigida por el Horas Akhenatón, después de haber roto con el clero de Amón, al instaurar de nuevo cuño una religión monoteísta al Atón (disco solar). En la citada ciudad se encuentra en su conjunto planimétrico el palacio real, la ciudad obrera, la residencial de altos dig-

16 Revillout, E.: Précis du droit Ėgyptien. Giard/Briére. París, 1903.

17 PIRENne, J.: Histoire des Institutions et du droit privé de l'Ancienne Ėgypte. FERE. Bruxelles, 1932.

* ThEODORIDES, A.: Les contracts d'Hâpidjefa. RIDA t. XVIII (1971). 
natarios y funcionarios, la religiosa del Atón. En una palabra, una ciudad "moderna" indiferenciada, aunque sin la organización de un comercio al por menor, que aún no se conocía, con lo cual las propias viviendas debían disponer de silos para el grano, establos, corrales, hornos y cuantos elementos fuesen necesarios para el autoabastecimiento y alimentación primaria.

Pendlebury ${ }^{19}$ ha publicado una reconstrucción idealizada (figura 9) del centro de la ciudad, donde se aprecia a la derecha del dibujo, el palacio

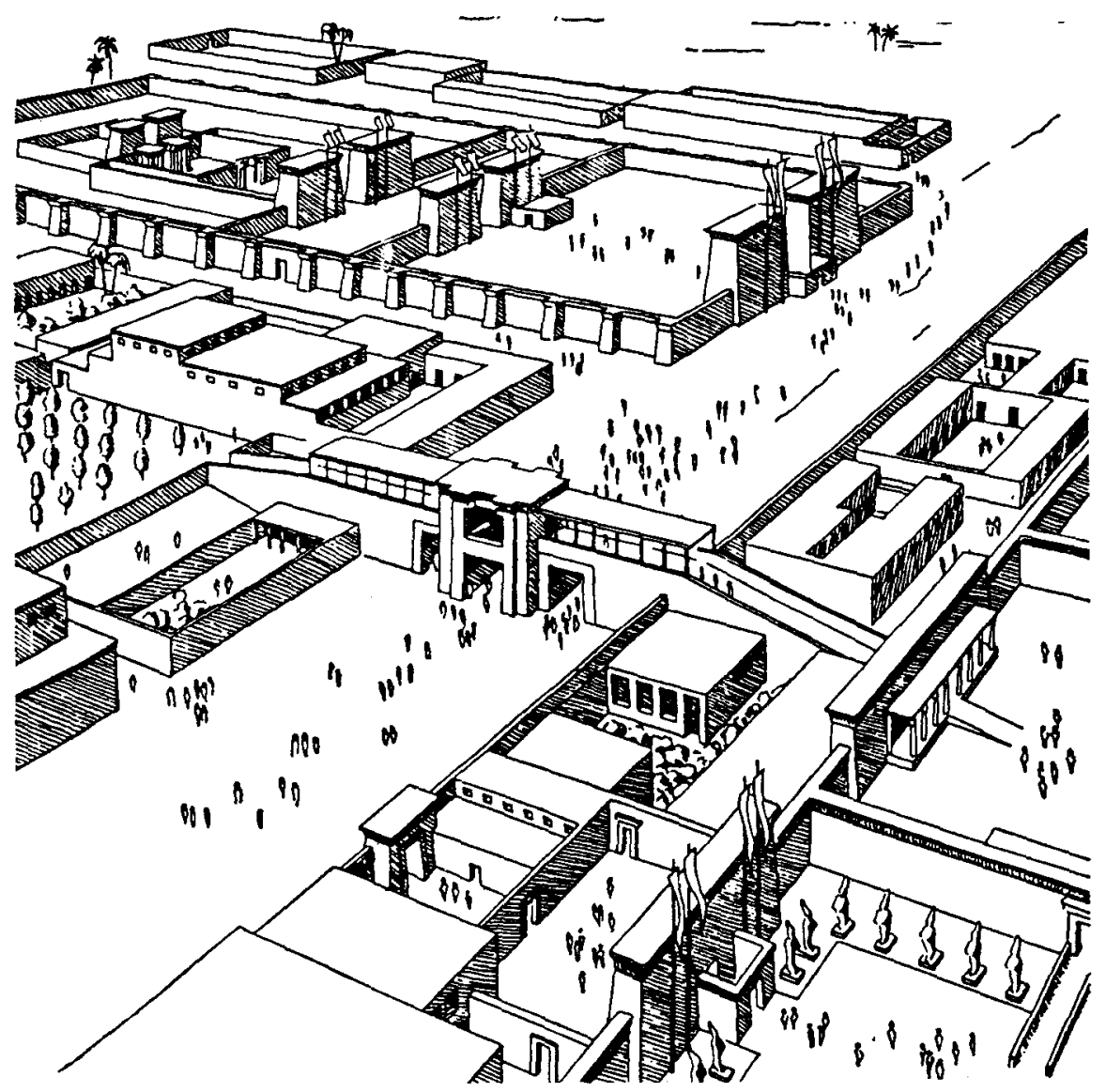

Figura 9.

19 Pendlebury: Les fouilles de Tell el Amarna. T. III. París, 1936. 


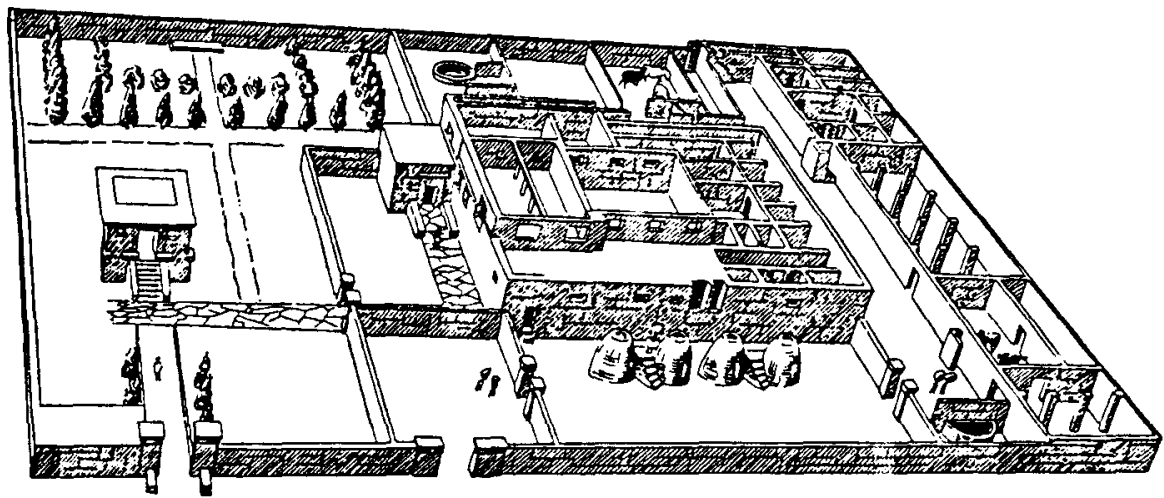

Figura 10.

real; a la izquierda el barrio de los funcionarios, y uniendo ambas construcciones, en el centro, el «balcón de las apariciones», donde el Horas repartía sus dádivas. Y Smith ${ }^{20}$ nos ha idealizado la lujosa villa del «T3ty» ${ }^{21}$ Nakht, primer ministro o jefe de gobierno de Akhenatón (figura 10), basada en la fotografía que se realizó poco después de ser excavada en 1922 (figura 11), y donde podemos observar su construcción de ladrillo de adobe, que explica la práctica desaparición de ese tipo de arquitectura, en contraposición a la persistencia de la arquitectura eclesiástica

Aldred ${ }^{22}$ siguiendo a Flinders Petrie, publica un plano central de «El horizonte de Atón», nombre que recibió la nueva capital fundada por Akhenatón en la llanura de Amarna (más conocida por Tell el-Amarna) que nos permitimos reproducir (figura 12), tal y como nos ha llegado gracias a la estela de Bek y Men en Aswan ${ }^{23}$ (figura 13).

Amarna ha sido exhaustivamente explorada, excavada y estudiada. Ya Richard Lepsius, discipulo de Champollión, hizo dos visitas al lugar, en

20 SMith, W. S.: The Art and Architecture of ancient Egypt. Penguins Books, 1958.

21 Para un mejor conocimiento de las trasliteraciones vid mi obra «El derecho de familia en el Egipto faraónico». Ut supra.

22 ALDRED, C.: Akhenatón. Thames and Hudson. London, 1988.

23 Se trata de una amplia estela tallada probablemente en el año $9^{\circ}$ de Akhenatón sobre un bloque de granito que se encuentra situada bajo el hotel Catarata, en la ribera oriental del Nilo, en Aswan (hoy depositada en el Museo de Berlín) y que al volver la hegemonía religiosa de Amón, fue debidamente martillada, borrando la figura de Akhenatón incensando al Atón. En ella se ve como el jefe de los escultores en tiempos del Horus Nebmare' (Amenhotep III "1408/1372"), Men, y su hijo Bek, jefe de escultores de Neferkheperure (Amenhotep IV/Akhenatón), rinden pleitesía a ambos Horus, el primero ya "justificado". 


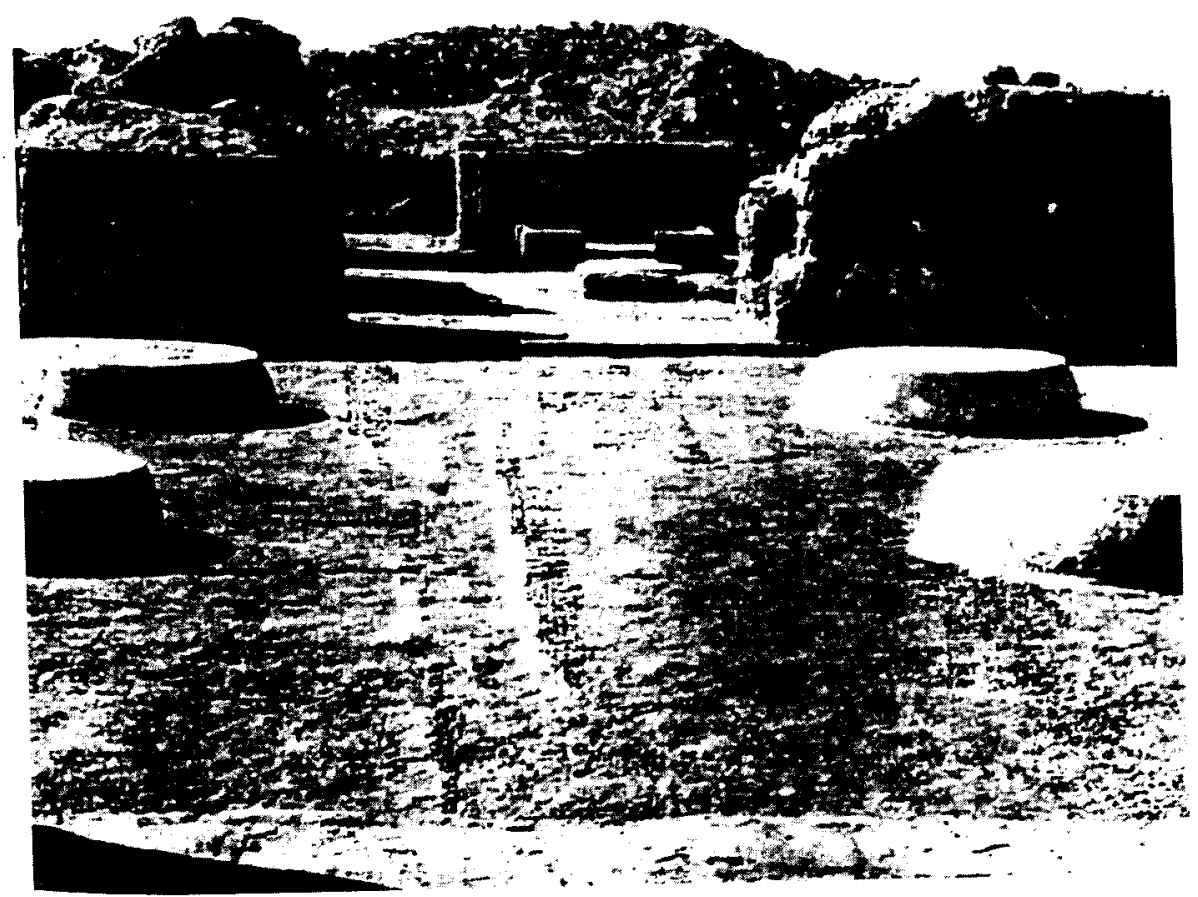

Figura 11.

1843 y 1845 , copiando inscripciones y esquemas de los relieves de las tumbas, y cuyos cuadernos se recopilaron luego en Berlín ${ }^{24}$, y que son, en gran parte, lo único que nos queda después de la destrucción y desaparición de muchos de los lugares allí reseñados.

Quizás la mejor forma de hacernos una idea, lejanamente parecida a cómo podía ser la vida cotidiana de las ciudades egipcias, concretándonos al ejemplo de Amarna, sea analizar el mapa descrito y dejar viajar a la imaginación, siempre que la constriñamos a mediados del siglo xIV a.C. Sólo nos queda observar (figura 14) una visión aérea y general de los restos de "El horizonte del Atón», para darnos cuenta de cómo pudo ser una ciudad "nueva», y relativamente populosa, hace nada menos que 3.500 años.

Ramsés II, 80 años más tarde expolió “El horizonte del Atón” ordenando demoler los edificios públicos y los templos transportando los

24 Lepsius, R.: Denkmaeler aus Aegypten und Aethiopen. Berlin (1849/59). 12 vol. + 5 vol. de texto $(1897 / 1913)$. 


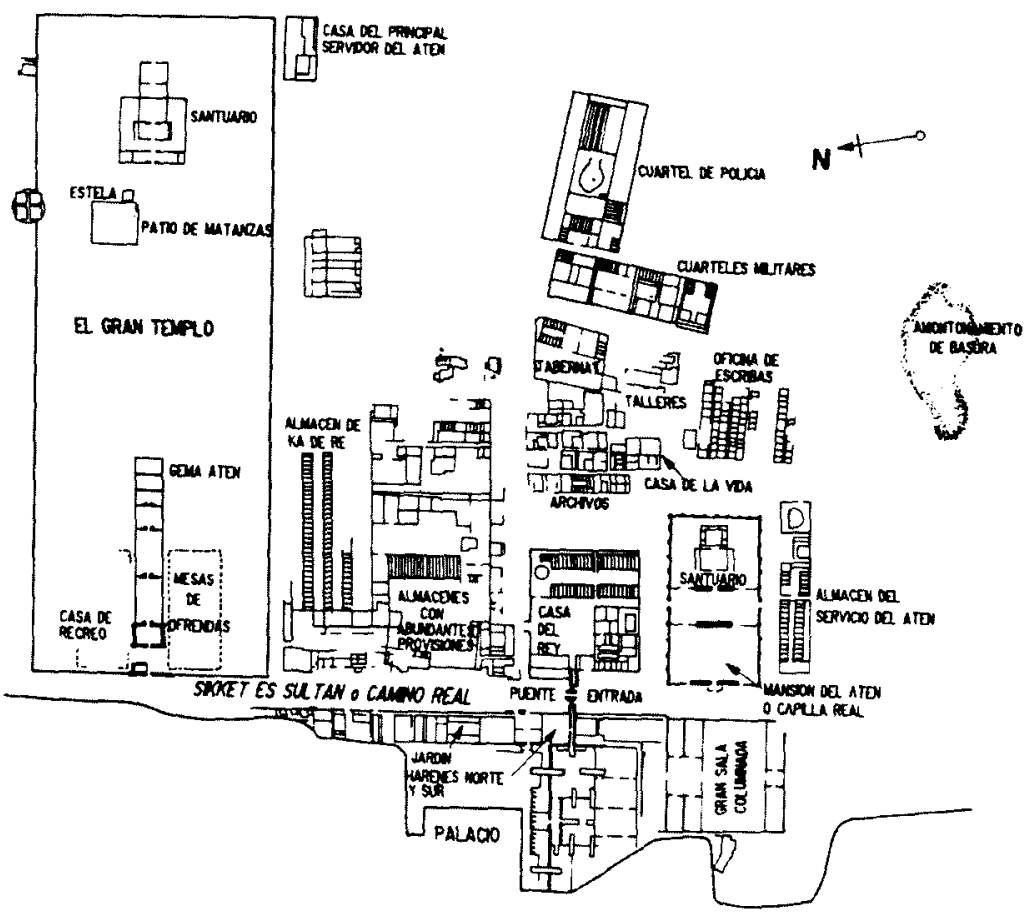

Figura 12.

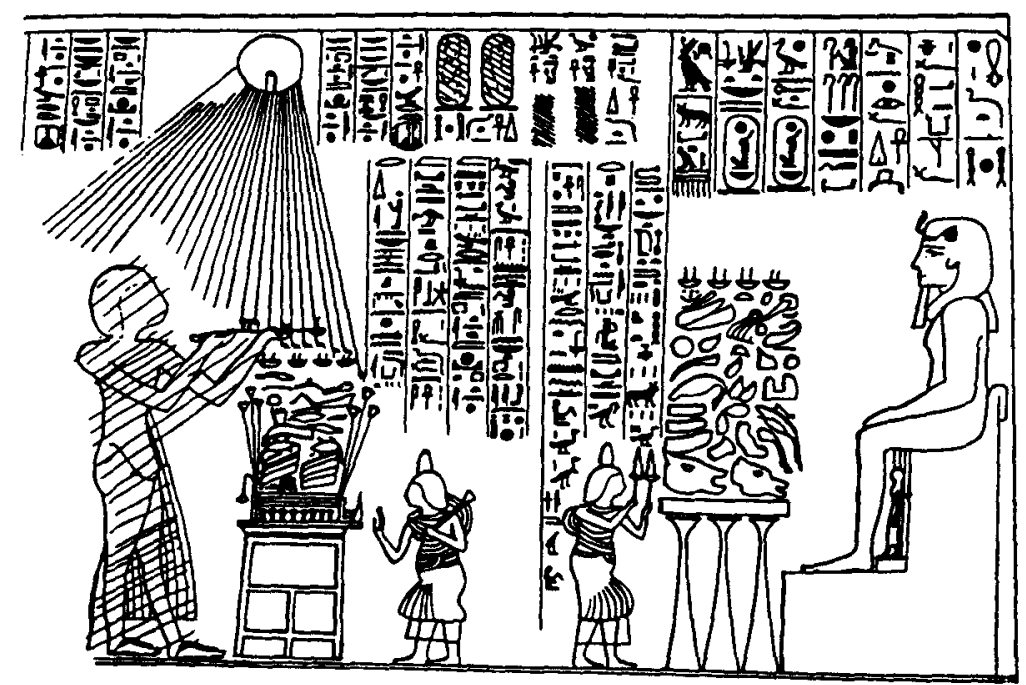

Figura 13. 


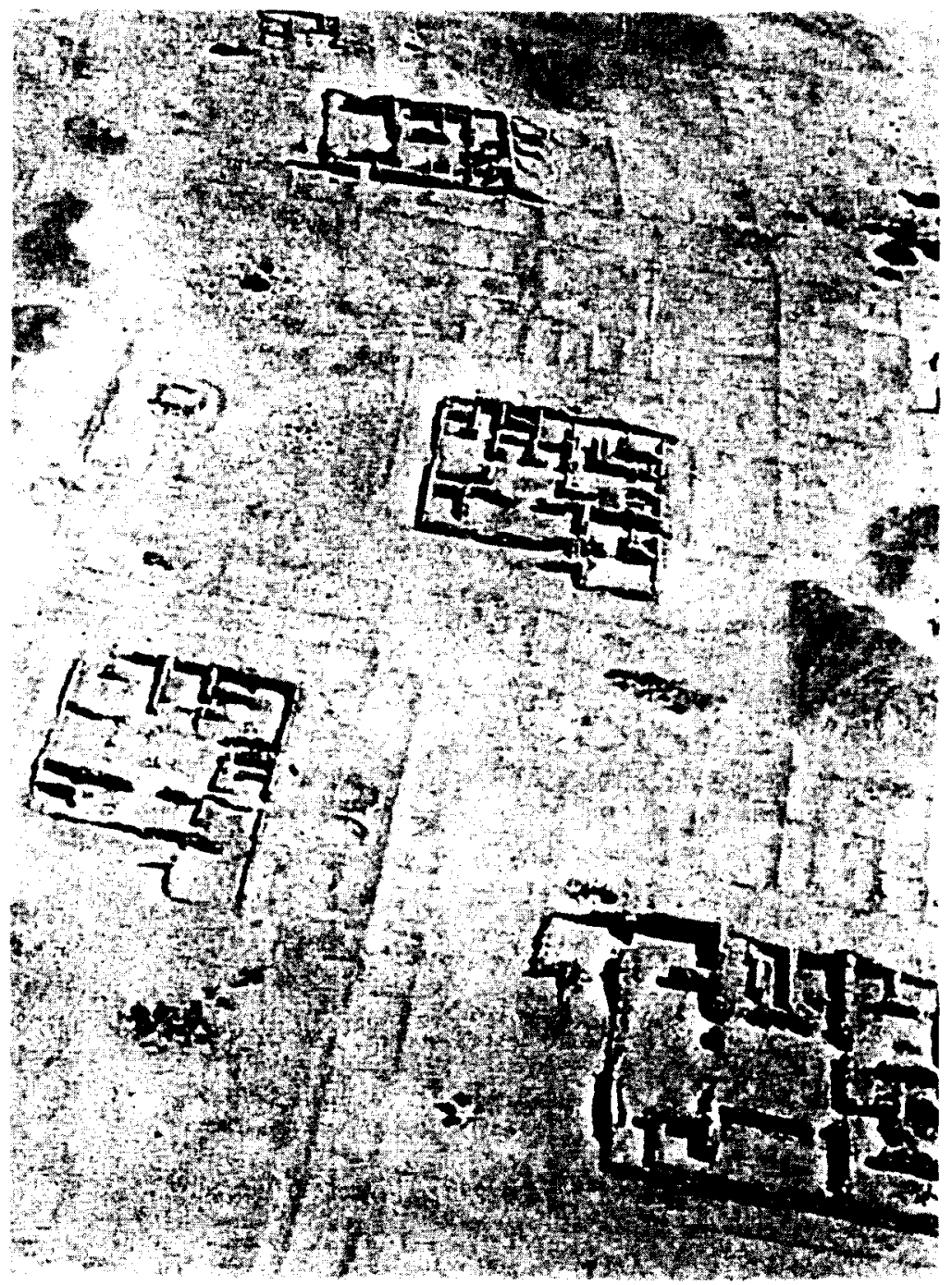

Figura 14.

bloques de piedra tallada en barco, por el río, y utilizándolos como material de relleno y cimentación en su megaprograma de construcción de templos. Los arqueólogos han sacado a la luz más de 1.500 bloques, muchos de los cuales están aún sin clasificar en los sótanos de los museos, y ello nos da una idea que cómo pudo ser la ciudad de Akhetatón. 
Al pie de los riscos que rodean a la ciudad y cerca de las tumbas rocosas, existió una pequeña aldea cuadrangular y amurallada con 68 casas que denota la existencia de una "ciudad artesana", que daba albergue a los artesanos y decoradores de tumbas de Amarna y que ha sido excavada por la Egypt Exploration Society inglesa.

\section{LAS CIUDADES-FORTALEZA}

Ya a comienzos del Imperio Medio y hacia el 1991 a.C. el Horus Sehetepibre (Amenemhet I, instauró la XII dinastía y en ella sobrevino la sumisión Nubia a Egipto ${ }^{25}$. Como consecuencia de este evento se fortificó, entre la 1. ${ }^{a}$ y la $2 .^{a}$ catarata, Buhen (hoy cubierta por la presa Nasser), ya en época de Kheperkare', 1970/1936 a.C. (Sesostris I, en la frontera con los nómadas beduinos medjai, y ahí se dio origen a una ciudad amurallada que se caracterizó por una arquitectura sobria y poco lujosa, a modo de defensa con el «misero país de Kush». Tanto Buhen (figura 15), como Semna y Aniba, como avanzadillas de Elefantina (figura 16), y esta misma, además de ciudades-fortaleza se caracterizaron por ser hitos en las rutas caravaneras y comerciales, con mercaderías centroafricanas que nos hace imaginar un bullicioso trajinar entre las guarniciones egipcias y los comerciantes nubios, y de otras procedencias, celebrando negocios y agasajándose con tortas cocidas y cerveza.

La ciudadela defensiva de Buhen medía $150 \times 138$ m., rodeada de una muralla de adobe de $5 \mathrm{mt}$. de espesor y con torreones, encerrando ese perímetro todo un conglomerado de casas, callejuelas empedradas y surcadas de recovecos a veces difíciles de interpretar urbanísticamente.

Elefantina, con una superfície de cerca 80 hectáreas en el Imperio Medio, ha sido suficientemente investigada y excavada exhaustivamente por el Instituto Alemán de Arqueología desde 1974, y se sabe que estuvo protegida por una muralla oval, con puerta de entrada junto al puerto, comercial y expedicionario. Como el resto de las ciudades descritas en cuanto a su estructura urbanística no cabe mencionar especiales características, y sirve, en términos generales, cuanto hemos dicho para el resto de ciudades fortaleza. Lo más llamativo era el exiguo número de villas de re-

25 Más tarde Khakaure (Sesostris III) 1887/1850, hará grabar en una estela fronteriza en Semna: "Yo establecí mi frontera remontando el río más arriba que mi padre. Soy un rey que no sólo habla, sino que actúa; Me llevé como botín de guerra a las mujeres nubias. Bebí sus aguas. Maté sus toros. Arranqué y quemé sus cereales...". 


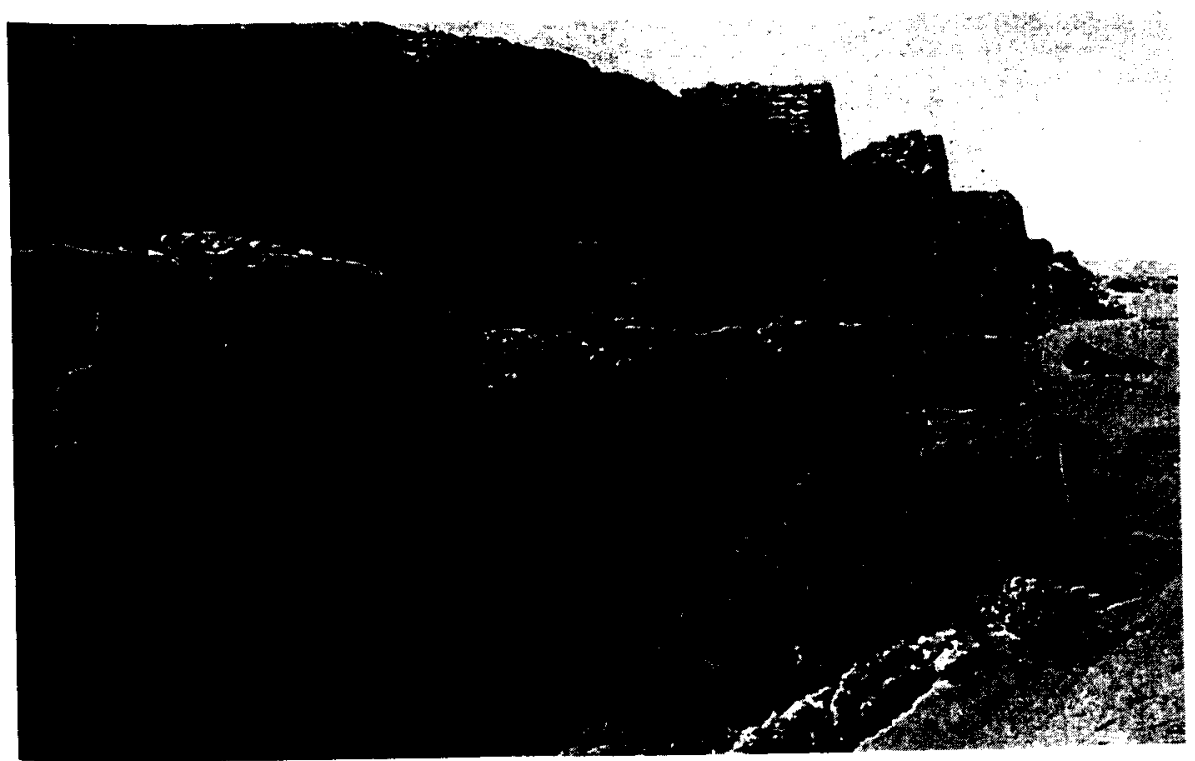

Figura 15.

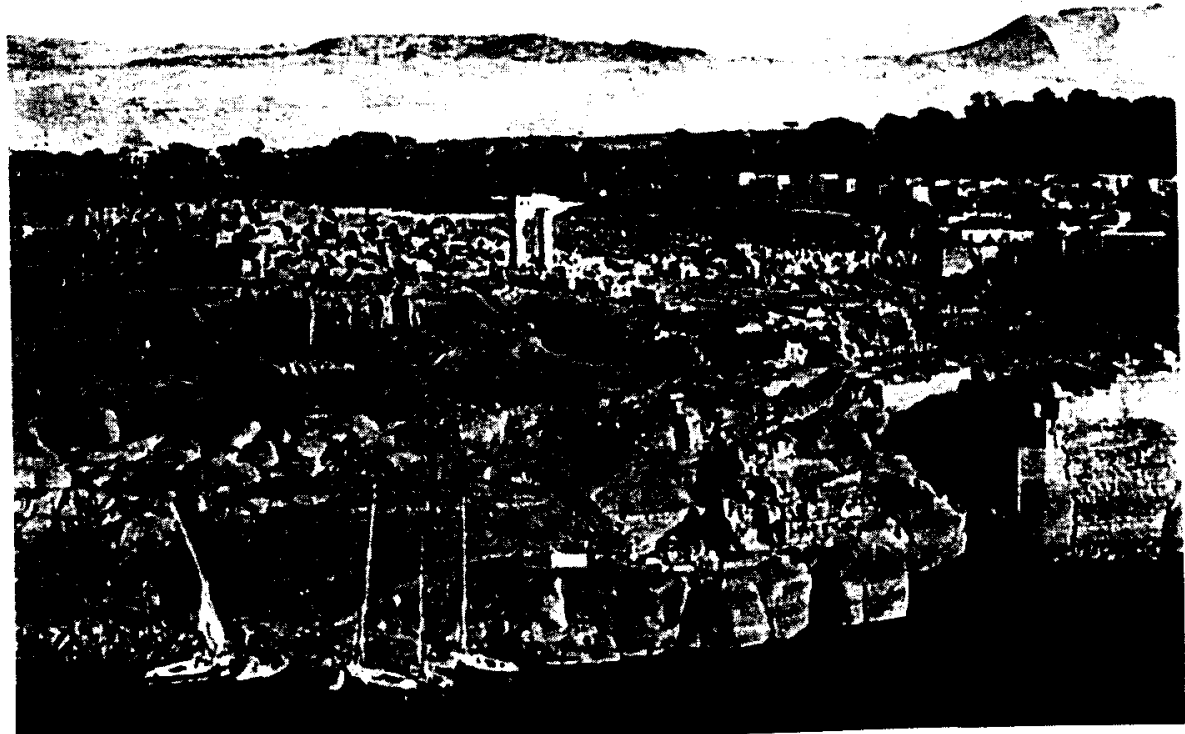

Figura 16. 
creo o casas suntuosas, si excepcionamos las correspondientes al nomarca, superintendente y algún funcionario de gran categoría, y el templo dedicado al dios local y las viviendas sacerdotales, fundamentalmente la referida al rango de Primer sacerdote. Pero sí podemos decir, de modo general que, excepto los templos, siempre de piedra, tanto la arquitectura, como los materiales de construcción de aquellas épocas, poco se diferencian en las viviendas humildes de las actuales, a pesar del tiempo transcurrido: La piedra de cantera, el adobe, la madera y los troncos de palmera y esteras de junco, junto a mobiliarios elementales, conforman una casa provincial egipcia.

\section{LAS CIUDADES-ARTESANOS}

Las mejor conocidas y estudiadas son "La ciudad de los obreros" de Deir el-Medina (figura 17) y "La ciudad de los obreros" de Kahun. Su excavación se ha hecho con metodología científica y gracias a ello disponemos de datos planigráficos y estatigráficos que nos dan una idea de cómo pudo ser su estructura y la vida de sus habitantes. Deir el-Medina, traducido del árabe "convento de la ciudad", fue excavado por el Instituto francés de arqueología oriental de El Cairo, entre 1917 y 1951. La ciudad es más bien un poblado, si nos guiamos por el número de habitantes permanentes que alli había: Entre 40 y 120 artesanos, desde su comienzo a principios de la XVIII dinastía hasta el final de la época ramésida; es decir, el Imperio Nuevo (1580/1085 a.C.). No conocemos la fluctuación de habitantes pero la oscilación antedicha puede ser correcta. Habría que añadir que aunque en deteminados momentos trabajaran, en tumbas y templetes de la necrópolis del Valle de los Reyes, muchos más obreros, el resto procedía de lugarejos vecinos, hoy inexistentes.

Puede que esta ciudad/artesana sea quien mejor nos informe sobre la vida cotidiana en el Egipto faraónico, por lo que, tras la descripción de la ciudad de Kahun, será el momento de iniciar el desarrollo sobre el ciudadano en Egipto y sobre la organizacion, administración y economía del mismo.

Kahun es el nombre que da Petrie a un asentamiento del Imperio Medio situado muy cerca de la actual ciudad de El-Lahun. Ya en su época, Kahun fue un asentamiento poblacional importante, no solamente de obreros y sacerdotes, destinados al culto funerario de la pirámide de Khakeperre', 1906/1888 a.C. (Sesostris II), sino como comunidad diversificada y urbanizada con una organización muy completa. Los papiros allí encontrados (y algunos aún en fase de traducción y estudio) así lo confir- 


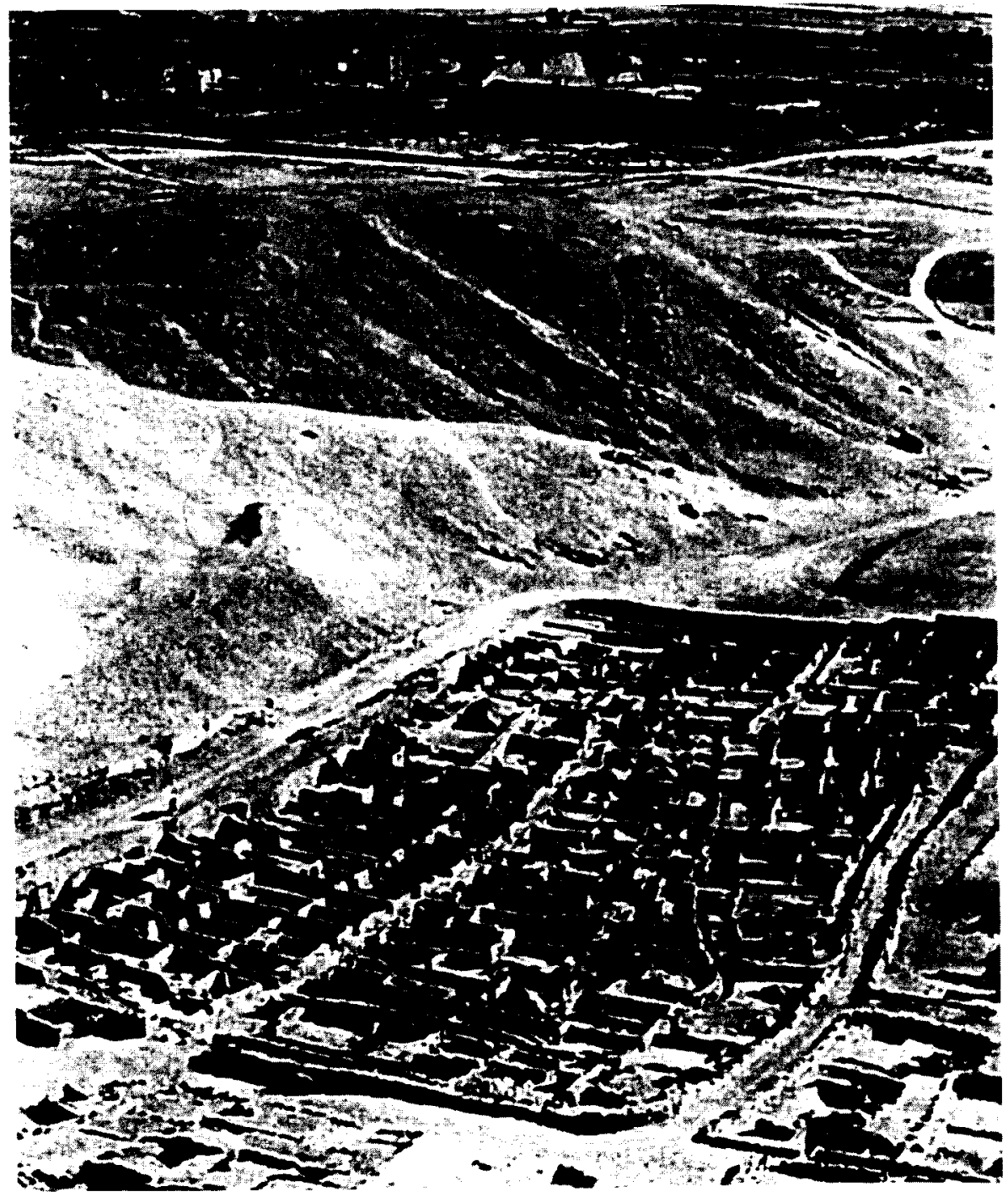

Figura 17.

man. El tamaño de la ciudad, de planta cuadrangular, media $384 \times 335 \mathrm{~m}$., y si bien aparenta estar amurallada, no estaba fortificada., si nos guiamos por los planos que dibujó Petrie.

En términos generales, podemos decir que las viviendas correspondientes a estas ciudades presentaban una distribución interior de un con- 
torno rectangular, dentro del cual se combinaban complicados y entrelazados espacios rectangulares, que no serían otra cosa que habitaciones destinadas a dormitorios, cuyos accesos eran resueltos con laberinticas soluciones. No solia faltar el patio ajardinado, en ocasiones con árboles, y la columnata de madera que formaba un pórtico dador de sombra. A veces las columnas estaban pintadas, e incluso esculpidas como haces de tallos papiráceos, capullos de loto coloreados e imitaciones de troncos de palmeras.

¿Qué número de habitantes pudo tener Kahun? Es muy difícil hacer un cálculo de relativa exactitud. Pero podría darse, por los datos que da Kemp ${ }^{26}$, que oscilarían entre los 2.500 y 3.000 habitantes.

Que se trataba de una ciudad estructurada lo acreditan los diversos tipos de edificios públicos. Así se identificó una oficina del «H3ty», una oficina administrativa o "W3ret", una "casa del juicio" y una cárcel.

Mucho más se podría describir sobre el tema pero los límites puestos al trabajo impiden mayores y más profundas descripciones.

\section{EL CIUDADANO}

No podemos generalizar, aunque sí vulgarizar, el "status" del ciudadano en Egipto. Tres mil años de historia son muchos para eso. De modo que, al objeto de dar una idea muy poco científica del egipcio medio, diremos que la sociedad se dividía en clases sociales, refiriéndonos a su "status" económico y administrativo. Dentro de éste (y desde luego con la influencia de aquél) podía distinguirse el grupo de funcionarios, el militar y el sacerdotal. A veces en determinadas personas estos grupos podían confundirse ( $y$ de hecho se confundían: Un alto cargo militar solia ser sacerdote de algún templo o deidad, y los altos funcionarios igualmente) por lo que el hacer un estereotipo demasiado rígido nos impediría la comprensión de la sociedad egipcia (en el Imperio Nuevo, por ejemplo) y del pleno desarrollo de sus actividades. Además estaba el campesinado, los artesanos y los siervos y esclavos (no muy numerosos, en contra de lo que se ha dicho por historiadores marxistas definiendo a Egipto como una sociedad esclavista).

El egipcio, debido a la benignidad del clima iba semidesnudo. Sólo en ocasiones determinadas (fiestas, reuniones de índole político-administrati-

${ }^{26}$ Kemp, B. J.: Ancient Egypt. Routledge. London, 1989. 
va, religiosas, cortesanas, etc.) se cubría con diversos tipos de vestidos: Generalmente un simple taparrabos, pero los grandes personajes, en festividades y actos oficiales, llevaban una gran falda de rebutos, y las mujeres una túnica tubular ceñida, otras con túnicas anchas, transparentes y con grandes frunces y flecos y, las más de las veces, una falda de la cintura a los tobillos, con los senos al aire, y sujeta por tirantes. A veces las mujeres se cubrian el sexo con una braga. Otras, no. La braga está documentada desde el Imperio Medio, pero probablemente su uso no estuvo excesivamente extendido. Por lo menos entre la ciudadana común. Pero, naturalmente, hay que decir que ya en aquellas épocas la moda imponía su ley. Así, en la época amarniense se estiló en el hombre la falda corta, estrecha y con un delantal trapezoidal delantero, llamado "shendit", también la falda larga y fruncida, camisa de anchas y cortas mangas, y ceñida con un cinturón. Los sacerdotes solían llevar una piel de pantera sobre el hombro. Respecto al calzado iban generalmente descalzos, y sólo en determinados lugares o momentos se calzaban sandalias, incluido el Horus.

La clase humilde, los fellahs o campesinos, los obreros y los marineros, generalmente iba desnuda 0 , como mucho, un taparrabos. $Y$ los niños, hasta la pubertad, siempre, perteneciesen a familias acaudaladas o a la clase más humilde. Ahí está para acreditarlo la estela de donación de Karnak ${ }^{27}$, o el talatat martillado, y utilizado como cimiento en uno de los pilonos de Karnak, representando a Nefertiti, besando a una de sus hijas, que se encuentra completamente desnuda ${ }^{28}$, y otro tanto hay que decir de las princesas Meritatón, Meketatón y Ankhesenpaatón, hijas de la anterior y Akhenatón, y cuya acreditación está en la caliza tallada que se encuentra en el museo egipcio de Berlín.

La alimentación, generalmente y como dieta cotidiana, era muy simple en las clases más bajas y mucho más variada en las clases altas: El pan común se hacía con harina de "bdt" (es decir, el llamado "Triticum dicoccum»), o incluso con «swt» (un trigo más fino, que si bien no podemos identificarlo con seguridad, podría ser el denominado "Iriticum aestium"). La miel era muy apreciada y su conservación se hacía en vasijas selladas. Hasta la introducción y manufactura del olivo, mediado el Imperio Nuevo, el aceite más utilizado en la cocina fue el de «b3k» (nuez egipcia, procedente del árbol autóctono "moringa") y el de sésamo, así como bolas

27 Vid Alonso Royano, F.: "Instituciones familiares....", donde se describe la Estela en la que se ve al niño Amosis, hijo del Horus Amosis, cogiendo a su padre del dedo índice de la mano derecha, con el peinado infantil (un mechón de pelo sobre el parietal derecho), completamente desnudo.

${ }_{28}$ Vid, Alonso Royano, F., ut supra. 
de grasa animal o sebo. La leche de vaca, burra u oveja era muy utilizada, y con su manufactura se hacía mantequilla, cuajada y queso. Se utilizaba mucho la carne de "iw3", un buey panzudo, corto de patas y rechoncho que se cebaba fácilmente; y algo menos el buey «ng3». El agua del Nilo producía algunas especies de peces muy apreciadas que, cuando no se consumían de inmediato, eran conservadas en salazón. Los huevos de ganso también eran muy utilizados. En cuanto a la cerveza, su preparación está en relación directa con el pan, dado que el proceso de elaboración era el mismo, y se trataba de la bebida más consumida en Egipto. Según nos han descrito los autores antiguos, la cerveza egipcia era una bebida alcohólica de sabor dulce, aunque había varios tipos, pues Estrabón nos habla de la amarga cerveza nubia que se agriaba fácilmente y que se bebía en burdeles y tabernas portuarias entre obreros y artesanos.

El vino («irp») se conoce desde los primeros tiempos dinásticos y se dispone de suficientes escenas funerarias sobre la vendimia y elaboración de esta bebida, y en el Imperio Nuevo los vinos procedentes del Delta y del oasis de Kharga, fueron muy apreciados. La clase rica también bebía vinos de importación.

Los productos hortícolas más utilizados fueron las lechugas, consideradas afrodisiacas, las habas y los garbanzos, que no comían los sacerdotes (y tampoco el cerdo), guisantes, lentejas, ajos, puerros, cebollas, melones, alubias, coles, rábanos, uvas, dátiles e higos.

Ya desde la época tinita (3000/2778 a.C.) cada nomo poseia un "dj3dj3t" (tribunal de justicia) lo que acredita la existencia de la administración de justicia, y por ende la existencia de normas legales de aplicación social ${ }^{29}$. No hemos de olvidar que para la concepción monárquica egipcia, el Horus ${ }^{30}$ era hijo y heredero de los dioses, frecuentemente Amón y Ra', y como dios viviente dictaba las leyes a sus administrados, como garante de "M3 $\cdot{ }^{31}$. De modo que el ciudadano egipcio, desde los primeros tiempos parece haber sido administrado $y$, por tanto, con un orden socioeconómico y político debidamente establecido.

29 Vid infra Bibliografia: Alonso RoyanO, F.: “El derecho de familia...”, "La protección jurídica...", "El arbitraje en el Egipto".

30 Utilizo este vocablo por considerar que va desde las dinastias dinásticas, el concepto de "rey" o "señor de tierras y hombres recibía el nombre de "Horus" que era la forma solar del "rey-dios" y una de las formas de designación real, ya que la expresión "faraón", que ha llegado a nuestros días, es de origen griego, que traduce la expresión egipcia "P3r3" y hebrea "Farón". $Y$ en copto antiguo "Furon".

${ }^{31}$ Diosa de la verdad y la justicia, llevando una pluma en la cabeza representa el orden cósmico. Dependiendo de las épocas fue madre o hija de Ra'. 
Dado que el derecho es el garante del orden social, nos interesa destacar para la comprensión del comportamiento social del ciudadano egipcio, que en el aspecto territorial la organización administrativa se dividía en 38 "S.p3t" (nomos o "provincias"). Pero algunos autores ${ }^{32}$ sostienen que eran 42 , en consonancia con los 42 jueces del tribunal de Osiris. Probablemente tengan razón. El derecho egipcio mantuvo una fuerte carga de derecho agrario y consuetudinario a lo largo de su desarrollo histórico y no recibió influencias extranjeras hasta el dominio ptolemaico, y aún así lo griego se egiptizó suficientemente como para que en el derecho procesal se produjeran dos tipos de tribunales y de procesos: el griego y el egipcio ${ }^{33}$.

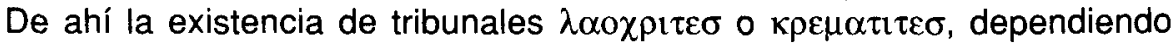
de que los asuntos relativos a los contratos matrimoniales con claúsula $\sigma \psi-$ $\gamma \rho \alpha \pi \eta \varepsilon \tau \rho \circ \pi \eta \tau \tau, \sigma$, se encontraran redactados en lengua egipcia o en lengua griega, y se planteara un litigio de divorcio garantizando una «s'nh" ${ }^{34}$.

Ya en esta época del Egipto ptolemaico los tribunales civiles estaban formados por un Magistrado, Presidente de Sala o A $\rho \chi \eta 1 \delta ı \kappa \alpha \sigma \tau \varepsilon \sigma$, un

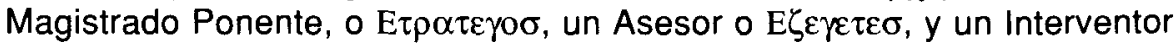

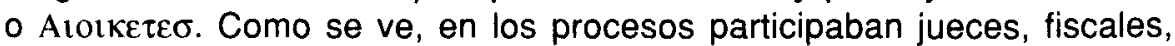
acusadores privados y representantes de las partes. $Y$ lo mismo se puede decir de épocas muy anteriores, con la existencia de «wp.w» (jueces), «c. $n$ wp.w» (casa del juicio) y «knb·t» (tribunal).

Aunque sabemos de la existencia de la célula familiar desde los más lejanos tiempos, pues como asegura Pirenne ${ }^{35}$ hacia el siglo XLV a.C. Ios hombres debieron practicar la cría de ganado, aprender a contar, establecer un calendario y organizar los casamientos, ciertamente coincidimos con Kingsley ${ }^{36}$ en que «mientras las instituciones económicas, políticas y educativas son estudiadas intensivamente, se dedica muy poco lugar al estudio de la familia. No existe nombre alguno para la ciencia de las relaciones de familia como institución social». Puede que lo que apunta Kingsley se deba a que la familia no sea un aspecto simplemente instrumental, sino en definitiva, último de la vida social, además de la faceta de intimidad e individualidad de la célula familiar. Sin embargo se nos antoja

32 JAQ, C.: L’Egypte des grands pharaons. Librairic Academique Perrin. París, 1981.

33 Vid. Alonso Y RoYano, F.: El contrato de compromiso en el derecho matrimonial egipcio. MHA. XV/XVI. U. de Oviedo, 1994/95.

${ }_{34}$ Bienes de alimentación, en demótico, garantizados por el marido a la mujer a través de un "sh n dh3 hd", o escrito de pago. Lo que hoy denominamos en derecho matrimonial pensión de alimentos.

35 Pirenne, J.: Civilizaciones antiguas. Caralt. Barcelona, 1967.

36 KingsLeY, D.: La sociedad humana. Universitaria de B.A. Buenos Aires, 1986. 
complicado el estudio de la sociedad humana sin el adecuado estudio de la familia y de las instituciones que la conforman. De modo que sería imposible definir al ciudadano y su entorno si no le contemplamos como sujeto de familia. Sin embargo el nacimiento de la familia, como formalidad gestual, ceremonial o documental, lo conocemos muy mal respecto a Egipto. No sabemos cómo se celebraba el matrimonio egipcio tanto en su aspecto puramente civil como religioso. Pero de acuerdo con Théodoridés ${ }^{37}$ es indudable la existencia de determinadas formalidades sancionadas por un contrato prescrito por la ley, según los modelos que nos han llegado ya desde la época ramésida, y cuyo colofón fuese una fiesta familiar más o menos sonada, dependiendo del status social y económico de las familias de los contrayentes; y a través de esos documentos podemos inferir que el matrimonio egipcio no dejaba de ser una institución jurídicoeconómica, adaptada a reglas consuetudinarias reconocidas por la autoridad competente que devenían eficaces al asegurar la ejecución de las decisiones que hubieran tomado los particulares.

\section{BIBLIOGRAFIA ESPECÍFICA PERO NO EXHAUSTIVA}

AlDRED, C.: Akhenaten. Thames and Hudson. London, 1988.

ALONSO y ROYANO, F.: Instituciones familiares en el Egipto faraónico (Tesis doctoral). UNED. Madrid, 1994.

- El derecho de familia en el Egipto faraónico. Lepsius. Valencia, 1995.

- El derecho de familia en el Egipto faraónico. EUE. Bilbao, 1996.

- Aspectos histórico-jurídicos del derecho y sus instituciones (4. edic.). EUE.

- La figura jurídica de la dote en el derecho matrimonial egipcio.: BICAR, $n^{\circ} 7$.

- La protección jurídica en el Egipto faraónico. TC, $n^{\circ}$ 5. Vigo, 1994.

- El arbitraje en el Egipto faraónico. III CPHA. UPV. Vitoria, 1994.

- El contrato de compromiso en el derecho matrimonial egipcio. MHA. Vol. XV/XVI. Oviedo, 1994/95.

ArOLA, R. (coord.).: Arqueología de las ciudades perdidas. Salvat. Barcelona, 1992.

AVDIEV, V.I.: Historia económica y social del Antiguo Oriente. Akal. Madrid, 1986.

Daumas, F.: La civilisation de l'Egypte pharaonique. Arthaud. París, 1965.

Drioton, E. y Vandier, J.: L'Egypte. Presses Universitaires de France. París, 1938.

Eggebrecht, A.: El antiguo Egipto. Plaza y Janés. Barcelona, 1984.

Flinders Petrie, W. M.: llahum, Kahun and Gurub. London, 1981.

INIESTA, F.: Antiguo Egipto. La nación negra. Sendai. Barcelona, 1989.

Jouret, R. M.: Tebas, 1250 a.C. Alianza. Madrid, 1992.

Kemp, B. J.: Ancient Egypt. Routledge. London, 1989.

KINGSLEY, D.: La sociedad humana. Universitaria de B.A. Buenos Aires, 1986.

LEPSIUS, R.: Deukmaeler aus Aegypten und Aethiopen. Berlín, ¿fecha?

MASPERo, G.: En tiempos de Ramsés y Assurbanipal. Jorro. Madrid, 1913.

Pendebbury: Les fouilles de Tell el Amarna. T. III. París, 1936.

PIRENNE, J.: Histoire des Institutions et du droit privé de l'Ancienne Ėgypte. FERE. Bruxelles, 1932. 3 tomos

37 THÉODORIDÉS, A.: "Le droit matrimonial dans l'Egypte pharaonique». RIDA. T. XXIII (1976). 
ReVILloUt, E.: Précis du droit Ègyptien. Giaud/Briére. París, 1903.

RiCKE: Der Grundriss des Amarnawohnhauses. Leipzig, 1931.

SMITH, W. S.: The Art and Architecture of ancient Egypt. Penguins Books. London, 1958.

SOULlÉ, D.: “La ciudad y su población bajo los Ramsés (Tebas). Alianza Edit. Madrid, 1992.

THÉODORIDÉS, A.: Le droit matrimonial dans l'Egipte pharaonique. RIDA, t. XXIII. Bruxelles, 1976.

\section{ABREVIATURAS UTILIZADAS}

BICAR Boletín Informativo del Iltre. Colegio de Abogados de La Rioja. Logroño.

CA «Bizkaia» Centro Asociado de la UNED en Vizcaya. Portugalete (Vizcaya).

CPHA Congreso Peninsular de Historia Antigua. Vitoria.

EUE Ediciones Universitarias Extravagantes. Bilbao.

FERE Fondation Ėgyptológique Reine Elisabeth. Bruxelles.

MHA Memorias de Historia Antigua. Oviedo.

RIDA Revue Internationale des Droits de l'Antiquité. Diegem.

TC Tribuna de la Cultura. Vigo.

UNED Universidad Nacional de Educación a Distancia. Madrid.

UPV

Universidad del País Vasco. San Sebastián. 